\title{
Protein Profiling of Resistant and Susceptible Mutant Lines of Rice Variety Swarna in Response to Rhizoctonia solani AG1 IA Infection
}

\author{
Reeshu Singh ${ }^{1}$,Sumant Pratap Singh ${ }^{1 *}$, Ankit Singh², \\ Prabhat Kumar Singh ${ }^{1}$, D.K. Dwivedi ${ }^{1}$ and N.A. Khan ${ }^{1}$ \\ ${ }^{1}$ Department of Plant Molecular Biology and Genetic Engineering, A.N. D. University of \\ Agriculture and Technology, Kumarganj Ayodhya, -224229 (UP). \\ ${ }^{2}$ Department of Crop Physiology, A.N. D. University of Agriculture and Technology, \\ Kumarganj Ayodhya, -224229 (UP), India
}

*Corresponding author

\begin{abstract}
A B S T R A C T
Rice sheath blight, caused by Rhizoctonia solani, is one of the most devastating diseases for stable rice production in most rice-growing regions of the world. Currently, studies of the molecular mechanism of rice sheath blight resistance are scarce. Here, we used mutated rice population of the variety swarna induced by the sodium azide $\left(\mathrm{NaN}_{3}\right)$. The variability in disease reaction was observed among mutated rice lines. Out of the total 1000 mutant plants, 47 plants were screened that show low disease index, ranged between 0 to 5 were selected for next generation. In $\mathrm{M}_{1}$ generation the selected genotypes show differences for disease index, only 12 lines shows resistance in $\mathrm{M}_{1}$ generation in field condition and in humidity chamber condition only 8 lines shows resistance. The protein analysis by SDS-PAGE showed that the resistance lines have one extra band in between 33 $\mathrm{kDa}$ and $43 \mathrm{kDa}$ that is not showing in moderate and susceptible lines. Thus, these resistance lines could be considered a potential source for disease resistance against the sheath blight of rice and could be used further in the crossing programme for development of sheath blight resistant rice variety.
\end{abstract}

\section{Keywords}

Mutation, Disease screening, Sheath blight, Resistance, Protein profiling

Article Info

Accepted:

xx August 2020

Available Online:

xx September 2020

\section{Introduction}

Rice is the most important cereal crop and it is a staple food for millions of people in the world (Chakravarti et al., 2012; Davla et al., 2013). Consumption of rice accounts for over $90 \%$ of the world's population in Asia, with China, India and Indonesia producing
$30.85 \%, 20.12 \%$ and $8.21 \%$, respectively of total global rice production (Kadu, et al., 2015). More than 70 diseases caused by fungi, bacteria, viruses or nematodes have been recorded on rice, among which rice blast (Magnaporthe grisea), bacterial leaf blight (Xanthomonas oryzae pv. oryzae) and sheath blight are the most serious constraints on high 
productivity (Ou, 1985). Rhizoctonia solani Kühn is a widespread soil-borne pathogen that causes economically important diseases in many crops (Adams, 1988). Rice sheath blight caused by $R$. solani is one of the most serious diseases of rice worldwide, causing considerable yield losses (Sudhakar et al., 1998). The widespread adoption of new, susceptible, high yielding cultivars with large numbers of tillers, and the changes in cultural practices associated with these cultivars, favor the development of sheath blight and contribute greatly to the rapid increase in the incidence and severity of this disease in riceproducing areas throughout the world (Groth et al., 1991). Furthermore, environmental conditions such as low light, cloudy days, high temperature and high relative humidity also favor the disease (Ou, 1985).

Mutation breeding involves the development of new varieties by generating and utilizing genetic variability through chemical and physical mutagenesis (Kharkwal et al., 2009 and Forster et al., 2012). Sodium azide $\left(\mathrm{NaN}_{3}\right)$ is a chemical mutagen and has been one of the most powerful mutagens in crop plants (Wen and Liang, 1995). It is known to be highly mutagenic in several organisms, including plants and animals (Rines, 1985; Raicu and Mixich, 1992; Grant and Salamone, 1994) and its mutagenic potential has been reported in several screening assays. Sodium azide is marginally mutagenic in different organisms (Arenaz et al., 1989). The mutagenicity is mediated through the production of an organic metabolite of azide compound (Owais and Kleinhofs, 1988). This metabolite enters into the nucleus, interacts to DNA, and creates point mutation in the genome (Kleinhofs et al., 1978; Gichner and Veleminsky, 1977). Being a strong mutagen in plant, it affects the different parts of the plants and their growth developmental phenomena by disturbing the metabolic activities (Salim et al., 2009).

\section{Materials and Methods}

\section{Plant materials}

The seeds of rice variety Swarna were collected from Department of Genetics and Plant Breeding, College of Agriculture, Acharya Narendra Deva University of Agriculture and Technology, Kumarganj, Ayodhya. India. Chemical mutagen sodium azide was used as a mutagen in this experiment. The $0.01 \%, 0.02 \%, 0.03 \%$, $0.04 \%, 0.05 \% \mathrm{NaN}_{3}$ solution were prepared and record the lethal dose $50\left(\mathrm{LD}_{50}\right)$ and $\mathrm{pH}$ adjusted with ortho-phosphoric acid. The mutated seeds treated with $0.03 \% \mathrm{NaN}_{3}$ were grown in nursery and later on healthy seedlings were transplanted in main fields at 21days of growth stage. The genotypes were screened under field conditions and humidity chamber condition in Kharif season for two consecutive years i.e. 20016-17 and 2017-18 for selection of resistant genotypes against $R$. solani. In M1 generation, individual plant represents one single genotype. Some potent mutant genotypes were selected based on the disease evaluation from 1000 plant population, consisting both mutant and control lines and their seeds were harvested separately. In $\mathrm{M}_{2}$ generation, disease resistance of selected mutants was confirmed by growing progeny to row method. The genotypes depicting very disease index value have been advanced to next generation $\left(\mathrm{M}_{2}\right)$. Control lines of swarna (non-mutated) were grown along with the mutated lines for resistance screening.

\section{Fungal isolate and inoculums preparation}

The most aggressive isolate A-1 of Rhizoctonia solani, isolated from the Rice Pathology Laboratory, Indian Institute of Rice Research, Hyderabad (Telangana) India, was taken for resistance screening. After placing sclerotia of $R$. solani onto Potato Dextrose 
Agar (PDA) under aseptic conditions, cultures were grown at $25 \pm 2^{\circ} \mathrm{C}$ under continuous light. Mycelial bits or immature sclerotia taken from 7 day old culture were cut and used as inoculums.

\section{Screening of sheath blight (ShB) under field condition}

Inoculation procedure for infection in cultivated varieties of rice and wild rice by $R$. solani isolates was performed according to Park et al., (2008). Immature sclerotia developed on 4-6 days old mycelia of $R$. solani strain D-14 was grown on Potato Dextrose Agar (PDA) medium. An immature sclerotium of $R$. solani was placed underneath the leaf sheath with $10 \mathrm{ml}$ of sterilized water. Inoculated and non-inoculated plants were placed in humidified chamber condition at $28 \pm 1^{\circ} \mathrm{C}$ for $24 \mathrm{hrs}$. Scoring of disease was carried out on 0-9 rating scale (Standard Evalution System of IRRI) as described below:

$0=$ absolutely free from infection

$1=$ lesions limited to lower $20 \%$ of plant height

$3=20-30 \%$ disease

$5=31-45 \%$ disease

$7=46-65 \%$ disease

$9=$ more than $65 \%$ disease.

\section{Protein profiling from leaves of mutant rice plant}

All chemicals for analytical work were of AR grade. Sodium phosphate buffer $(0.25 \mathrm{M}, \mathrm{pH}$ 7.0), containing $0.15 \mathrm{~N} \mathrm{NaCl}$, mutant rice leaves, pestle and mortar, ice, centrifuge tubes etc. The rice leaf protein was isolated as method described by (Laemmli et al., 1970). The fresh plant leaf were cut into small pieces using razor and crushed in sodium phosphate buffer (0.25M, pH 7.0) containing $0.15 \mathrm{~N}$. It was homogenized mechanically and centrifuged at $10,000 \mathrm{~g}$ at $4^{0} \mathrm{C}$ for 20 minutes. This process was done twice. After centrifugation the supernatant was collected. This supernatant was crude rice leaf protein.

\section{Gel electrophoresis}

The separating gel were put between glass plates up to proper mark and wait for 30- 40 minutes for proper polymerization of gel. The stacking gel was cast, after polymerization of separating gel, insert the Teflon comb (13 well) in the gap between the glass plates and wait for proper polymerization of the stacking gel. After proper polymerization the Teflon comb was carefully removed from the gel and plates were assembled into electrophoresis unit and electrode buffer was filled both in lower and upper tank of electrophoresis unit. After this the electrophoresis unit was attached with power pack and placed the gel for 8-10 hours with a supply of $25 \mathrm{~mA}$ and 160 volt current. When the tracking dye reached the end of the running gel after complete separation of protein molecules, power supply turned off. The gel was gently removed from the space between

\section{Gel analysis of protein}

The relative mobility of the different protein bands were recorded by comparing the bands with standard protein marker loaded with gel.

\section{Results and Discussion}

\section{Disease screening of sheath blight (ShB) of $M_{1}$ generation under field condition}

Out of 1000 mutant rice plants of Swarna, 47 rice mutants plant showed resistance $(\mathrm{R})$, in $\mathrm{M}_{1}$ population. The disease reaction and phenotypic expression were observed among the mutant population. Similarly mutation induced lines of variety Mahsuri were released for blast resistance with improved 
cooking and eating qualities. (Hadzim, et al., rice cultivar showed the significant 1994; Hadzim, et al., 1988; Faruq et al., improvement in disease resistance to blast and 2003). The screening of mutant line Zhe-101 selected from the mutant progenies of Indica bacterial blight (Wen-chao et al., 2004).

Figure.1 Showing disease infection in field condition of mutant rice plant

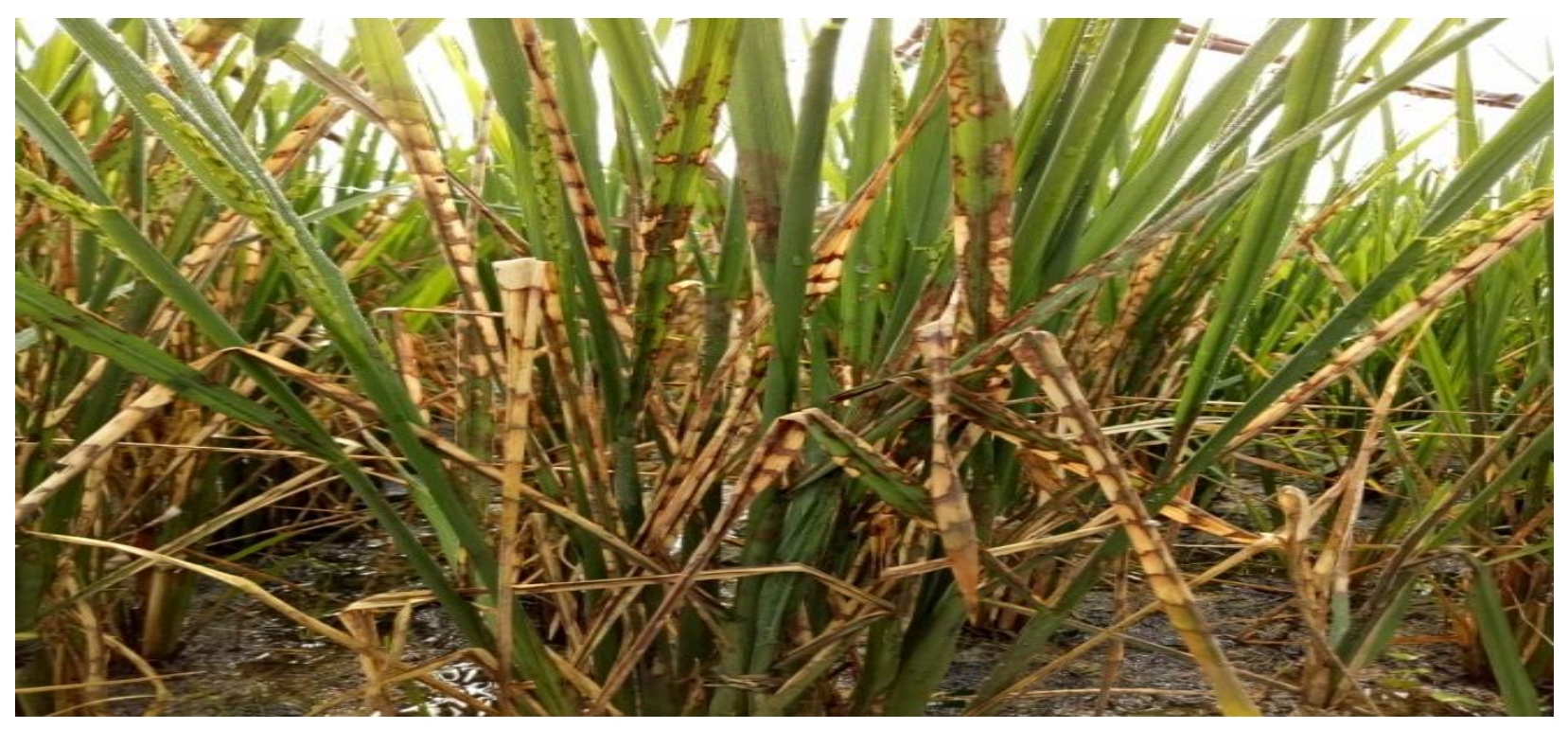

Figure.2 Protein profiling of control, moderately susceptible, susceptible and resistance mutant lines. M-Marker, C- Control, MS- Moderately Susceptible, S- Susceptible, HS- highly Susceptible, R-Resistance (1R, 2R,3R,4R are showing different resistant mutant lines)

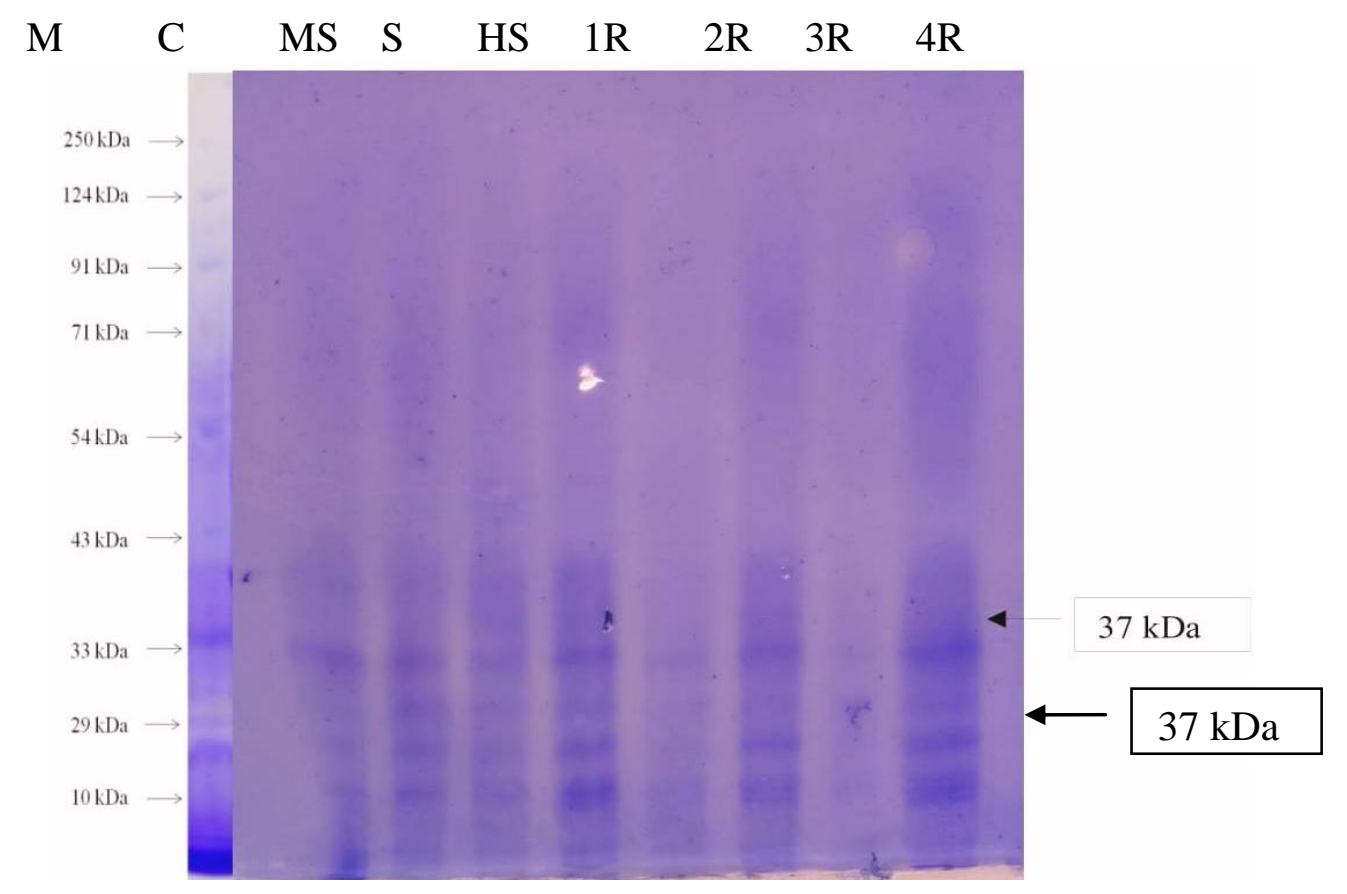


Table.1 Showing different banding pattern of mutant rice plant in $\mathrm{kDa}$

\begin{tabular}{|c|c|c|c|c|c|c|c|c|c|}
\hline S.No. & M & Control & MS & S & HS & $\mathbf{1 R}$ & $\mathbf{2 R}$ & $\mathbf{3 R}$ & $\mathbf{4 R}$ \\
\hline $\mathbf{1}$ & 250 & - & - & - & - & - & - & - & - \\
\hline $\mathbf{2}$ & 240 & - & - & - & - & - & - & - & - \\
\hline $\mathbf{3}$ & 200 & - & - & - & - & - & - & - & - \\
\hline $\mathbf{4}$ & 190 & - & - & - & - & - & - & - & - \\
\hline $\mathbf{5}$ & 150 & - & - & - & - & - & - & - & - \\
\hline $\mathbf{6}$ & 124 & - & - & - & - & - & - & - & - \\
\hline $\mathbf{7}$ & 110 & - & - & - & - & - & - & - & - \\
\hline $\mathbf{8}$ & 92 & - & - & - & - & - & - & - & - \\
\hline $\mathbf{9}$ & 91 & - & - & - & - & - & - & - & - \\
\hline $\mathbf{1 0}$ & 90 & - & - & - & - & - & - & - & - \\
\hline $\mathbf{1 1}$ & 89 & - & - & - & - & - & - & - & - \\
\hline $\mathbf{1 2}$ & 85 & - & - & - & - & - & - & - & - \\
\hline $\mathbf{1 3}$ & 80 & - & - & - & - & - & - & - & - \\
\hline $\mathbf{1 4}$ & 79 & - & - & - & - & - & - & - & - \\
\hline $\mathbf{1 5}$ & 75 & - & - & - & - & - & - & - & - \\
\hline $\mathbf{1 6}$ & 72 & - & - & - & - & - & - & - & - \\
\hline $\mathbf{1 7}$ & 71 & - & - & - & - & - & - & - & - \\
\hline $\mathbf{1 8}$ & 60 & - & - & - & - & - & - & - & - \\
\hline $\mathbf{1 9}$ & 55 & - & - & - & - & - & - & - & - \\
\hline $\mathbf{2 0}$ & 54 & - & - & - & - & - & - & - & - \\
\hline $\mathbf{2 1}$ & 53 & - & - & - & - & - & - & - & - \\
\hline $\mathbf{2 2}$ & 44 & - & - & - & - & - & - & - & - \\
\hline $\mathbf{2 3}$ & 43 & - & - & - & - & - & - & - & - \\
\hline $\mathbf{2 4}$ & 40 & - & - & - & - & - & - & - & - \\
\hline $\mathbf{2 5}$ & 37 & & - & & & 37 & & - & 37 \\
\hline $\mathbf{2 6}$ & 34 & - & - & - & - & - & - & - & - \\
\hline $\mathbf{2 7}$ & 33 & 33 & 33 & 33 & 33 & 33 & 33 & - & 33 \\
\hline $\mathbf{2 8}$ & 32 & - & - & - & - & - & - & - & - \\
\hline $\mathbf{2 9}$ & 30 & - & - & - & - & - & - & - & - \\
\hline $\mathbf{3 0}$ & 29 & 29 & 29 & 29 & -- & - & 39 & - & 29 \\
\hline $\mathbf{3 1}$ & 28 & - & - & - & - & - & - & - & - \\
\hline $\mathbf{3 2}$ & 25 & 25 & - & 25 & 25 & 25 & - & - & 25 \\
\hline $\mathbf{3 3}$ & 22 & - & - & - & - & - & - & - & - \\
\hline $\mathbf{3 4}$ & 20 & - & - & - & - & - & - & - & - \\
\hline $\mathbf{3 5}$ & 19 & - & - & - & - & - & - & - & - \\
\hline $\mathbf{3 6}$ & 18 & - & - & - & - & - & - & - & - \\
\hline $\mathbf{3 7}$ & 15 & - & - & - & - & - & - & - & - \\
\hline $\mathbf{3 8}$ & 14 & - & - & - & - & - & - & - & - \\
\hline $\mathbf{3 9}$ & 12 & - & - & - & - & - & - & - & - \\
\hline $\mathbf{4 0}$ & 11 & - & - & - & - & - & - & - & - \\
\hline $\mathbf{4 1}$ & 10 & 10 & 10 & 10 & 10 & 10 & 10 & 10 & 10 \\
\hline & & & & - & & - & & & \\
\hline
\end{tabular}


Disease screening of sheath blight in $M_{2}$ generation of $M_{1}$ selected plants under field condition

Screening in $\mathrm{M}_{2}$ generation of $\mathrm{M}_{1}$ selected plants in field condition four types of genotypes were found on the basis of disease reaction. In $\mathrm{M}_{2}$ generation out of 47 mutants genotyped we found 12 resistance (R), 15 moderate resistance (MR), 15 moderate susceptible (MS) and 5 susceptible (S) lines. This data was recorded by taking mean value of 5 plants from every row of specific genotype. These identified mutant lines could be considered being a potential source for disease resistance against the sheath blight of rice according to Mosaddeque et. al., (2008) conducted that studies on forty-four test entries of parental lines of rice with one susceptible and one resistant check were screened against sheath blight. Ten lines were resistant, 31 were moderately resistant and 3 showed moderately susceptible reaction at maximum tillering stage (Fig. 1 and 2; Table $1)$.

\section{Protein profiling of mutant rice plant on basis of diseases reaction}

The protein profiling showed that the not mutant and mutant line. Mutant line classified on the basis of disease reaction against sheath blight resistance and susceptible lines. Maximum lines shows similar band, only $1 \mathrm{R}$ and $4 \mathrm{R}$ mutant line show extra band in between $33 \mathrm{kDa}$ and $43 \mathrm{kDa}$.

The band intensity is high in resistance as compare to moderate and susceptible mutant lines of rice variety Swarna result supported by Li et al (2011).The result on the banding pattern of the protein profiles suggested that the specific genotype could be differentiated either based on the position or intensity of bands but not on number, as some of the varieties expressed similar number of bands, similar report supported that Netra and
Prasad, (2007).

\section{References}

Adams, G.C. (1988). Thanatephorus cucumeris (Rhizoctonia solani) a species complex of wide host range. In: Advances in Plant Pathology, vol. 6. (G.S. Sidhu, ed.), Academic Press, New York, NY, USA, 535-552.

Arenaz, P., Hallberg, L., Mancillas, F., Gutierrez, G., Garcia S., (1989). Sodium azide mutagenesis in mammals; inability of mammalian cells to convert azide to mutagenic intermediate. Mutation Research 277, 63-67.

Chakrawarti, S. K., Kumar, H., Lal, J. P. and Vishwakarma, M. K. (2012). Induced mutation in traditional aromatic ricefrequency and spectrum of viable mutations and characterizations of economic values. The Bioscan. 7(4): 739-742.

Davla, D., Sasidharan, N., Macwana, S., Chakraborty, S., Trivedi, R., Ravikiran, R. and Shah, G. (2013). Molecular characterization of rice (Oryza sativa L.) genotypes for salt tolerance using microsatellite markers. The Bioscan. 8(2): 498-502.

Faruq, G., Mohamad, O., Hadzim, K. and Craig, M.A. (2003). Optimization of Aging Time and Temperature of Four Malaysian Rice Cultivars. Pakistan $J$. Nutr. 2: 125-31.

Forster, BP and Shu ,QY. (2012). Plant mutagenesis in crop improvement: basic terms and applications. In: (Shu, QY., Forster, BP., Nakagawa, H., )Plant mutation breeding and biotechnology. Wallingford: CABI; p. 9-20.

Gichner, T., Veleminsky, J., (1977). The very low mutagenic activity of sodium azide in Arabidopsis thaliana. Biologia Plantarum 19, 153-155.

Grant, W.F., Salamone, M.F., (1994). Comparative mutagenicity of chemicals 
selected for test in the international program on chemical safety collaborative study on plant systems for the detection of environmental mutagens. Mutation Research 310, 187 209.

Groth, D.E., Rush, M.C. and Hollier, C. A. (1991). Rice diseases and disorders in Louisiana. Louisiana State University, Agricultural Center, Louisiana Agricultural Experiment Station, Bulletin No. 828. Baton Rouge, LA, USA.

Hadzim, K., Ajimilah, N.H., Othman, O., Arasu, N.T., Latifah, A. and Saad, A. (1988). Mutant Mahsuri: Baka untuk beras bermutu. Teknol. Padi. 4: 7-13.

Hadzim, K., Ajimilah,N.H., Othman, O., Arasu,N.T., Latifah A. and Saad, A. (1994). Mahsuri Mutant: Baka untuk beras bermutu. Teknol. Padi. 4: 7-13.

IRRI (2002) Standard Evaluation System For Rice. International Rice Research Institute, Manila.

Kadu, T. P., Kale, S. S., Chavan N. R., Agrawal, T., and Verulkar, S. B. (2015). Pyramiding of three bacterial blight resistance in Dubraj rice cultivar using marker-assisted selection The Ecoscan, VII: 07-12.

Khan S, Al-Qurainy F., and Anwar F.(2009) Sodium Azide: a Chemical Mutagen for Enhancement of Agronomic Traits of Crop Plants Environ. We Int. J. Sci. Tech. 4, 1-21.

Kharkwal, MC., Shu QY. (2009). The role of induced mutations in world food security. In: (Shu QY) Induced plant mutations in the genomics era. Rome: Food and Agriculture Organization of the United Nations; . p. 33-38.

Kleinhofs, A., Owais, W., Nilan, R.A., (1978). Azide; Mutation Research 55, $165-195$.

Laemmli, U.K, (1970). Cleavage of structure protein during the assembly of the head of bacteriophage T4. Nature 227:680685.

Li, Liu., Zhiming, Zhang., Maojun, Zhao., Jing, Wang., Hai-jian, Lin., Ya-ou, Shen and Guangtang, Pan (2011). Molecular cloning and characterization of pathogenesis-related protein 5 in Zea mays and its antifungal activity against Rhizoctonia solani. African Journal of Biotechnology 10 (83): 19286-19293.

Mosaddeque, H. Q. M., Talukder, M. I., Islam, M.M., Khusrul Amin, A. K. M. and Alam M. A. (2008). Screening of Some Restorer and Maintainer Hybrid Rice Lines against Sheath Blight (Rhizoctonia solani). J. Soil. Nature. 2(1): 23-29.

Netra N, Prasad S (2007). Identification of rice hybrids and their parental lines based on seed, seedling characters, chemical tests and gel electrophoresis of total soluble seed proteins. Seed Sci. Technol. 35: 176-186.

Ou, S.H. (1985). Rice Diseases. 2nd ed. Commonwealth Mycological Institute, Kew, UK, 380 pp.

Owais, W.M., Kleinhofs, A., (1988). Metabolic activation of the mutagen azide in biological systems. Mutation Research 197, 313-323.

Park, D. S., Sayler, R. J., Hong, Y. G., Nam, M. H., and Yang, Y. (2008). A method for inoculation and evaluation of rice sheath blight disease. Plant Dis. 92: 2529.

Raicu, P., Mixich, F., 1992. Cytogenetic effects of sodium azide encapsulated in liposomes on heteroploides cell cultures. Mutation Research 283, 215219.

Rines, H.W., 1985. Sodium azide mutagenesis in diploid and hexaploid oats and comparison with ethyl methanesulfonate treatments. Environmental and Experimental Botany 25, 7-16. 
Sudhakar, R., Rao, K. C. and Reddy, C. S. (1998). Studies on antagonism of Trichoderma and Gliocladium species against Rhizoctonia solani of rice. Indian Journal of Plant Protection, 26: 25-29.

Wen, J.G, Liang, H.G., 1995. Effect of KCN and NaN3 pretreatment on the cyanide resistant respiration in tobacco callus.
Acta Botanica Sinica 37,711-717. Wen-chao, Y., Guo-chang, S., Jian-long, X., Fa-ming,Y., Xue-qin, M., and Qingsheng, J.(2004). Breeding of a new Indica Rice Mutant line Zhe-101 for resistance to blast and bacterial leaf blight by space mutation. Chinese $J$. Rice Sci. 18(5): 415-419.

\section{How to cite this article:}

Reeshu Singh, Sumant Pratap Singh, Ankit Singh, Prabhat Kumar Singh, D.K. Dwivedi and Khan, N.A. 2020. Protein Profiling of Resistant and Susceptible Mutant Lines of Rice Variety Swarna in Response to Rhizoctonia solani AGI IA Infection. Int.J.Curr.Microbiol.App.Sci. 9(09): 3971-3978. doi: https://doi.org/10.20546/ijcmas.2020.908.457 